\title{
Reflexões histórica e epistemológica da Demonstração da Lei dos Senos e seus possíveis obstáculos ao conhecimento
}

\author{
Historical and epistemological reflections on the \\ Demonstration of the Law of Sines and its possible \\ obstacles to knowledge
}

\begin{abstract}
Reflexiones históricas y epistemológicas sobre la Demostración la de Ley de Senos y sus posibles obstáculos al conocimiento
\end{abstract}

\author{
Márcio Ponciano dos Santos \\ Secretaria de Educação do Estado da Bahia - SEEBa \\ Rio Real, Bahia, Brasil \\ E-mail: poncianomarcio@hotmail.com \\ Orcid: 0000-0002-4593-4179
}

Laerte Silva da Fonseca Instituto Federal de Educação, Ciência e Tecnologia de Sergipe, Campus Aracaju - IFS Aracaju, Sergipe, Brasil E-mail: laerte.fonseca@uol.com.br Orcid: 0000-0002-0215-0606

Ivanete Batista dos Santos Universidade Federal de Sergipe - UFS

São Cristóvão, Sergipe, Brasil

E-mail: ivanetebs@uol.com.br

Orcid: 0000-0001-6984-3661

Resumo: Os estudos sobre trigonometria impulsionam discussões que fomentam inúmeras pesquisas na área da Educação Matemática. Assim, levantou-se a hipótese da existência de obstáculos no processo de construção da Demonstração da Lei dos Senos. Nesta pesquisa, são apresentados os resultados de uma análise na história da trigonometria, destacando o estudo das cordas e dos ângulos como precursor do estudo da Lei dos Senos e, consequentemente, de sua demonstração. Para a condução metodológica, foi desenvolvida uma análise histórica e epistemológica para compreender o contexto e os obstáculos referentes ao conhecimento estudado. O arcabouço teórico apoiou-se nos conhecimentos sobre a história da matemática e em estudos referentes aos obstáculos epistemológicos. A partir da investigação, constatou-se a necessidade de se estudar os marcos a respeito da Lei dos Senos, pois os indícios demarcados na história da matemática apresentam poucos elementos para investigação desse campo do conhecimento. 
Palavras-chave: Demonstrações Matemáticas. Lei dos Senos. Obstáculos Epistemológicos.

Abstract: Studies on trigonometry drive discussions that foster numerous research in the field of Mathematics Education. Thus, the hypothesis of the existence of obstacles in the process of building the demonstration of the Law of Sines was raised. In this research, the results of an analysis in the history of trigonometry are presented, highlighting the study of strings and angles as a precursor to the study of the Law of Sines and, consequently, of its demonstration. For the methodological conduction, a historical and epistemological analysis was developed to understand the context and the obstacles related to the knowledge studied. The theoretical framework was based on the knowledge about the history of mathematics and studies concerning epistemological obstacles. From the research, the need to study the milestones concerning the Law of the Sines was noted, as the evidence demarcated in the history of mathematics presents few elements for research in this field of knowledge.

Keywords: Mathematical Demonstrations. Law of Sines. Epistemological Obstacles.

Resumen: Los estudios sobre trigonometría impulsan discusiones que fomentan numerosas investigaciones en el área de la Educación Matemática. Así, se planteó la hipótesis de la existencia de obstáculos en el proceso de construcción de la demostración de la Ley del Senos. En esta investigación se presentan los resultados de un análisis en la historia de la trigonometría, destacando el estudio de las cuerdas y los ángulos como precursor del estudio de la Ley del Senos y, en consecuencia, de su demostración. Para la conducción metodológica, se desarrolló un análisis histórico y epistemológico para comprender el contexto y los obstáculos relacionados con los conocimientos estudiados. El marco teórico se basaba en el conocimiento de la historia de las matemáticas y los estudios sobre los obstáculos epistemológicos. De la investigación se desprende la necesidad de estudiar los hitos de la Ley del Senos, ya que la evidencia demarcada en la historia de las matemáticas presenta pocos elementos para la investigación en este campo del conocimiento.

Palabras-chave: Demostraciones Matemáticas. Ley del Senos. Obstáculos Epistemológicos.

Recebido em

21/0115/12/2020

Aceito em

$21 / 02 / 2021$ 


\section{INTRODUÇÃO}

O presente artigo traz um recorte da dissertação Expectativas neurocognitivas da atenção em uma sequência de ensino para a habilitação do raciocínio axiomático durante a aprendizagem da Demonstração da Lei dos Senos, pesquisa que teve por objetivo analisar as expectativas neurocognitivas atencionais disponíveis durante 0 processo de construção do raciocínio axiomático utilizado na Demonstração da Lei dos Senos. Neste recorte, a finalidade é apresentar o resultado de uma análise na história da trigonometria, destacando o estudo das cordas e dos ângulos como precursor do estudo da Lei dos Senos e de sua demonstração.

A composição do levantamento histórico se deu mediante a revisitação das obras de Eves (2004), Euclides (2009) e Boyer (2012), com o intuito de buscar indícios de uma história que contemplasse a Demonstração da Lei dos Senos (DLS) para auxiliar na compreensão de sua epistemologia. A identificação dos obstáculos epistemológicos no desenvolvimento da DLS foi pautada nos estudos de Bachelard (1996) e Almouloud (2007), além de pesquisas que empreendem esforços em análises epistemológicas de tal natureza, como as de Fonseca $(2011,2015)$. Nessa perspectiva, levantaram-se as seguintes questões: existem vestígios, na história da trigonometria, a respeito do desenvolvimento da Demonstração da Lei dos Senos? Como a Lei dos Senos era utilizada pelas civilizações antigas?

Para responder a essas inquietações, fez-se necessário entender o contexto histórico da trigonometria, buscando destacar sua construção e compreender até que ponto os conhecimentos da DLS possibilitaram uma melhor compreensão dos conteúdos trigonométricos e sua relevância na resolução de problemas. Além da revisitação na história da matemática, a identificação dos obstáculos epistemológicos foi necessária para entender possíveis lacunas deixadas na construção desse objeto de conhecimento.

Nesse percurso, as seções que seguem explicitam com mais detalhes os passos seguidos para engendrar a garimpagem dessa análise e os resultados encontrados. 


\section{CARACTERIZAÇÃo históRICA SOBRE A Demonstração da LEI DOS SENOS}

$\mathrm{Na}$ estruturação dos parágrafos que seguem, foram enfatizadas considerações concernentes a vestígios da Lei dos Senos (LS) a fim de compreender e se familiarizar com o desfecho do estudo histórico desse conhecimento, visando a uma construção concisa e coesa de suas abordagens e permitindo demarcar o contexto das civilizações que fizeram parte do desenvolvimento da trigonometria.

Para identificar tais aspectos, foi analisado em livros didáticos de matemática do Ensino Médio como a LS é apresentada e, também, em livros científicos, teses e dissertações por serem os registros históricos mais acessíveis a respeito da temática investigada. Com efeito, a análise histórica permitiu (re)conhecer marcos do estudo das cordas dentro do ramo da trigonometria, justificando a importância desse ramo para a evolução científica e sua necessidade para as sociedades babilônica, egípcia e grega até chegar à atualidade. Mas poucos foram os indícios sobre a LS. O intuito desta investigação não é reescrever a história desse conhecimento, mas identificar as marcas deixadas ao longo da história no campo trigonométrico"

Das obras científicas analisadas, aquela que apresentou maior detalhamento a respeito da história da matemática foi a de Eves (2004); assim, por meio de estudos dessa obra, foi elaborada uma grade de análise (ver Quadro 1) que foi aplicada ao rastreamento histórico, permitindo alcançar os objetivos traçados nesta seção. O quadro a seguir evidencia as palavras que podem ser identificadas na obra visitada, as quais remetem a indícios da temática pesquisada.

\footnotetext{
${ }^{1}$ Nesta pesquisa, a expressão "campo trigonométrico" será usada para designar os achados e as interpretações dos pesquisadores relacionados ao objeto de pesquisa (DLS) que resultaram da articulação entre os conhecimentos de trigonometria presentes na Demonstração da Lei dos Senos.
} 
Quadro 1- Palavras-chave visitadas na história da matemática na obra de Eves (2004).

\begin{tabular}{|c|c|c|c|c|}
\hline Marcadores $^{2}$ & $\begin{array}{c}\text { Palavras- } \\
\text { chave na } \\
\text { história da } \\
\text { trigonometria }\end{array}$ & $\begin{array}{c}\text { Povos/ } \\
\text { Civilizações }\end{array}$ & Entendimento dos povos listados & $\begin{array}{l}\text { Paginação } \\
\text { em Eves } \\
\text { (2004) }\end{array}$ \\
\hline \multirow{3}{*}{ P1 } & \multirow{3}{*}{$\begin{array}{l}\text { Papiro Rhind ou } \\
\text { Ahmes } \\
\text { Tábua de } \\
\text { Plimpton } 322\end{array}$} & Egito & $\begin{array}{l}\text { Estudo das medidas das inclinações } \\
\text { (segt). }\end{array}$ & 83 \\
\hline & & Babilônia & Tábulas matemáticas babilônicas. & $63-66$ \\
\hline & & Grécia & Divisão do círculo em $360^{\circ}$. & 202 \\
\hline \multirow{4}{*}{ P2 } & \multirow{4}{*}{ Trigonometria } & Grécia & $\begin{array}{c}\text { Trabalhos especificamente } \\
\text { geométricos. Cálculo do comprimento } \\
\text { de cordas. }\end{array}$ & $203-214$ \\
\hline & & Índia & $\begin{array}{l}\text { Pautavam-se em uma trigonometria } \\
\text { mais aritmetizada. }\end{array}$ & $\begin{array}{l}248,257- \\
259,261\end{array}$ \\
\hline & & Arábia & $\begin{array}{c}\text { Foram responsáveis por preservar os } \\
\text { conhecimentos gregos mediante suas } \\
\text { traduções. }\end{array}$ & $264-266$ \\
\hline & & Europa & $\begin{array}{c}\text { Primeira exposição sistemática de } \\
\text { trigonometria plana e esférica, num } \\
\text { tratamento independente da } \\
\text { Astronomia. }\end{array}$ & $\begin{array}{l}296,312- \\
\quad 314\end{array}$ \\
\hline \multirow{4}{*}{ P3 } & \multirow{4}{*}{$\begin{array}{l}\text { Tábua de } \\
\text { Cordas/Tábuas } \\
\text { de Senos/ } \\
\text { Tábuas } \\
\text { Trigonométricas }\end{array}$} & Grécia & $\begin{array}{l}\text { Atribui-se a Hiparco um tratado em } 12 \\
\text { livros que se ocupa da construção de } \\
\text { uma tábua de cordas. A tábua de } \\
\text { cordas de Ptolomeu fornece os senos } \\
\text { dos ângulos de } 0^{\circ} \text { a } 90^{\circ}, \text { com } \\
\text { incrementos de } 15^{\prime \prime} .\end{array}$ & 203-204 \\
\hline & & Índia & $\begin{array}{c}\text { Construíam tábuas de semicordas e } \\
\text { não de cordas, como os gregos haviam } \\
\text { construído. }\end{array}$ & 248 e 259 \\
\hline & & Arábia & $\begin{array}{c}\text { Elaboraram notáveis tábuas de senos } \\
\text { e tangentes com incrementos de } 1^{\prime}, \\
\text { corretas pelo menos até a oitava casa } \\
\text { decimal. }\end{array}$ & 262 e 265 \\
\hline & & Europa & $\begin{array}{c}\text { Construção de duas tábuas } \\
\text { trigonométricas notáveis e ainda úteis } \\
\text { hoje. Uma delas envolve as seis } \\
\text { funções trigonométricas, calculadas } \\
\text { com dez casas, para intervalos de 10" } \\
\text { de arco; a outra é uma tábua de senos, } \\
\text { com } \\
15 \text { casas, para intervalos de 10" de } \\
\text { arco, juntamente com a primeira, a } \\
\text { segunda e a terceira diferenças. }\end{array}$ & 313-314 \\
\hline $\mathrm{P} 4$ & Lei dos Senos & & $\begin{array}{c}\text { Usado como sugestão das respostas } \\
\text { dos exercícios. }\end{array}$ & 749 e 764 \\
\hline
\end{tabular}

Fonte: Os autores (2019), investigação na obra de Eves (2004).

A princípio, foi realizada uma investigação no campo da geometria, identificando a trigonometria como um ramo dessa área do conhecimento. Os primeiros vestígios que

\footnotetext{
${ }^{2}$ Esses marcadores foram identificados no decorrer das leituras como palavras que evidenciam alguns indícios de aproximação com a temática da DLS.
} 


\section{Universidade Federal da Grande Dourados}

existem acerca da geometria datam da civilização egípcia, que justificava seus conhecimentos, em grande parte, por meio das conclusões experienciais e eram detidos pelos sacerdotes, intermediários entre a divindade e o povo (Eves, 2004).

Esses vestígios estão registrados nos problemas geométricos do Papiro de Ahmes ou de Rhind, datados de 1650 a.C., que apresentam várias aplicações e têm como base o uso de técnicas matemáticas para solucioná-los. Os egípcios já faziam uso de alguns termos que remetem atualmente a elementos da trigonometria. Boyer (2012, p. 36) destaca que "A palavra egípcia seqt significa o afastamento horizontal de uma reta oblíqua em relação ao eixo vertical para cada variação de unidade na altura". A partir dessa citação, é possível afirmar que o conhecimento dos egípcios sobre as medições de inclinação por meio de razões (primeiros vestígios da trigonometria) foi recorrente nessa época.

A civilização babilônica, que teve seu início em aproximadamente 2000 a.C., também deixou suas marcas no decorrer da história da matemática. Esses povos obtiveram grandes progressos, e muitos dos escritos dessa época estão preservados até hoje por utilizarem tábuas de argila que são mais resistentes ao tempo do que o papiro que era usado pelos egípcios. Um dos vestígios dessa civilização é a tábua de Plimpton 322, que se trata de um tipo de prototrigonometria (Eves, 2004).

Os conhecimentos herdados dos povos egípcios e babilônicos mostram os primeiros passos do surgimento da trigonometria, os quais foram de grande importância para o desenvolvimento dessas civilizações. No entanto, nos remetem a uma inquietação: como esses conhecimentos eram justificados para que fossem aceitos como verdadeiros?

Não há indícios que possam afirmar que os conhecimentos desses povos não levavam em consideração a natureza da demonstração ${ }^{3}$, pois "[...] os escribas préhelênicos não raro verificavam ou "demonstravam" suas divisões por multiplicação; ocasionalmente verificavam o método usado em um problema por meio de uma

\footnotetext{
${ }^{3}$ A palavra "demonstração" significa várias coisas em diferentes níveis e épocas; por isso, é arriscado afirmar categoricamente que os povos pré-helênicos não tivessem noção de demonstração, nem sentissem a necessidade de demonstração (Boyer, 2012, p. 50).
} 


\section{Universidade Federal da Grande Dourados}

substituição que confirmava a correção da resposta" (Boyer, 2012, p. 50).

De acordo com os estudos de Euclides (2009, p. 83), "[...] não encontramos, seja nos documentos egípcios seja nos babilônicos, [...], qualquer esboço do que se assemelhe a uma 'demonstração', no sentido formal do conceito". Nesse percurso, surgiu a ampla divergência entre ciência e senso comum, ocasionando a valorização das investidas em alicerçar os conhecimentos com fundamentos que não só possam ser justificados por meios empíricos, mas que sejam fruto de uma organização lógica. Segundo Eves (2004, p. 682):

[...] o formalismo considera a matemática como uma coleção de desenvolvimentos abstratos em que os termos são meros símbolos e as afirmações são apenas fórmulas envolvendo esses símbolos; a base mais funda da matemática não está plantada na lógica mas apenas numa coleção de sinais ou símbolos pré-lógicos e num conjunto de operações com esses sinais.

Assim, com "[...] os matemáticos da Grécia, a razão suplanta a empiria como critério de verdade e a matemática ganha característica de uma ciência dedutiva" (Euclides, 2009, p. 77). Os conhecimentos foram edificados mediante os estudos gregos, valorizando as justificativas e demonstrações por meio das estruturas lógicas, caracterizadas como "[...] a transformação do primitivo conhecimento matemático empírico de egípcios e babilônicos na ciência matemática grega, dedutiva, sistemática, baseada em definições e axiomas" (Euclides, 2009, p. 83).

A preocupação com uma organização lógica da matemática, de acordo com os estudos de Domingues (2002), aparece na Grécia, com Tales de Mileto (624-548 a.C., aproximadamente), responsável pela demonstração do teorema que leva seu nome, contribuindo com a organização dedutiva da geometria. A demonstração é marcada por duas grandes etapas: convencer, marco da antiga Grécia e, também, dos povos babilônicos e egípcios, todavia, em meados do século XVII, sua significação passa a ser esclarecer

Na Grécia, a ciência cresceu de forma livre. Assim, não bastava apenas ter a demonstração como um ato social de convencimento; as pessoas podiam questionar e buscar respostas que pudessem tornar as informações mais compreensíveis. Dessa forma, fez-se necessário o uso de teorias que pudessem não só convencer, mas que 
permitissem esclarecer os conhecimentos analisados.

Com o passar do tempo, o significado de demonstrar ultrapassa o que se considerou como esclarecer; logo, tornar evidente e certo chegou a um formalismo muito diferente de como era pensado na Grécia, uma vez que os objetos matemáticos definidos pelos meios axiomáticos não têm existência objetiva e se respaldam no princípio da não contradição (Euclides, 2009).

Uma das distinções entre a concepção grega e a concepção moderna de método axiomático reside na questão dos conceitos primitivos; para os gregos não havia uma lista de conceitos primitivos. Justifica-se esse procedimento pelo fato de que para os gregos a geometria não era exatamente um estudo abstrato, mas uma tentativa de análise lógica do espaço físico idealizado (Eves, 2004, p. 656).

A palavra trigonometria, de acordo com Eves (2004), tem sua origem na Grécia, como uma composição de trigonus (triângulo) e metrum (medida), cujo principal objetivo é estudar as relações entre os lados e ângulos de um triângulo. O surgimento dela vem da necessidade de se trabalhar conhecimentos como os de Astronomia, Agrimensura, Navegação, além de outros.

É nessa civilização que o estudo de tais relações tem um maior desenvolvimento por meio do raciocínio lógico-dedutivo com Hiparco de Nicéia (180 a.C. - 125 a.C., aproximadamente) e Claudius Ptolomeu (87 a.C. - 150 a.C., aproximadamente) com o estudo da trigonometria das cordas. De acordo com Eves (2004) e Boyer (2012), Hiparco escreveu uma obra com 12 livros referentes ao cálculo de comprimento de cordas, rendendo-Ihe o título de pai da trigonometria, porém sua obra não chegou até nossos tempos (Silva \& Pereira, 2016).

Acredita-se que a obra de Hiparco tenha servido de base para o astrônomo Claudius Ptolomeu, que escreveu Matematikes Syntaxis, e, por influência dos árabes, é conhecida como Almagesto, obra que apresenta a primeira tabela trigonométrica da qual se tem indícios. Esse trabalho foi escrito em 13 livros, destacando os estudos das cordas, numa época em que o geocentrismo era a teoria predominante.

$\mathrm{Na}$ antiguidade, a trigonometria aparece no cenário como ferramenta cuja finalidade era auxiliar a Astronomia. As principais abordagens desse conhecimento desvinculado da Astronomia foram marcadas pelo Tratado dos Quadriláteros de Nasir 
al-Din al-Tusi, no século XIII. Já na Europa, surge por meio de De triangulis omnimodis libri quinque de Regiomontanus, escrito por volta de 1464, com publicação em 1533 (Eves, 2004).

Segundo Boyer (2012), uma das primeiras aplicações usadas por intermédio dos conhecimentos de trigonometria plana foi o cálculo da distância da Terra em relação ao Sol e à Lua, sendo estudos realizados por Hiparco de Nicéia, além da elaboração de previsão de eclipses. Ademais, a determinação do nascer e desaparecer de várias estrelas por intermédio da tabela de cordas foi um dos feitos desse grande estudioso na antiguidade.

A realização do cálculo de distâncias muito grandes (astronômicas) sem a utilização de instrumentos de medidas adequados é um marco no desenvolvimento do povo grego, pois, ao fazerem uso de conhecimentos matemáticos, alcançaram tais feitos, chegando a resultados extraordinários. Assim, "Desde a antiguidade até hoje, o homem sempre teve a necessidade de avaliar distâncias inacessíveis" (Lima, Carvalho, Wagner \& Morgado, 2010, p. 68).

Em face dos indícios da trigonometria indiana, percebeu-se a enorme gama desses conhecimentos aplicados à Astronomia. Os hindus, contudo, apresentavam uma trigonometria voltada à aritmetização, diferentemente da grega, que era muito mais geométrica. A “[...] matemática hindu era grandemente empírica, raramente oferecendo uma demonstração ou uma dedução; a característica mais importante da matemática grega era sua insistência com as demonstrações rigorosas" (Eves, 2004, p. 259). Passados os anos, o uso das tabelas de cordas foi se configurando, e elas passaram a ser chamadas de tabelas de senos.

No Renascimento, séculos XIV e XV, a expansão marítima europeia teve uma grande influência da trigonometria no desenvolvimento da cartografia e da topografia. Com a mudança do sistema para o heliocêntrico (o Sol como centro do universo), houve a necessidade de se refazerem todos os cálculos da Astronomia posicional, mas com base nas ideias usadas no sistema geocêntrico. Na trigonometria, os estudos dos ângulos e das cordas eram os pontos fortes, visto que estiveram, em sua maioria, interligados a algum contexto de aplicação. Boyer (2012, p. 122-123) confirma 


\section{Universidade Federal da Grande Dourados}

essa passagem dizendo que "[...] diversos astrônomos da era alexandrina trataram problemas que indicam a necessidade de uma relação sistemática entre ângulos e cordas. Os teoremas sobre os comprimentos de cordas são essencialmente aplicações da lei dos senos moderna".

Nesse sentido, percebe-se que o estudo do comprimento das cordas está intimamente associado ao da Lei dos Senos (LS), a qual compreende o campo de investigação desta análise. Dessa maneira, tomando por base as obras de Eves (2004), Euclides (2009) e Boyer (2012), não foi encontrado um marco inicial do uso da DLS, mas somente a associação da Lei dos Senos (LS) ao se estudar o comprimento das cordas. Assim, essa lei é citada na resolução do exercício 4.6 (Aplicações do Princípio da Inserção) e do 10.8 (Curvas Planas Superiores), capítulos 4 e 10, respectivamente, da obra de Eves (2004).

Para uma melhor compreensão dos entendimentos históricos, foi organizado o Quadro 2, trazido a seguir, que evidencia os marcos visitados na história da trigonometria que serviram de base para a organização deste levantamento.

Quadro 2 - Principais marcos identificados na história da trigonometria.

\begin{tabular}{|c|c|c|c|}
\hline Marcador & Episódio Histórico (EH) & $\begin{array}{l}\text { Marcadores } \\
\text { do Quadro } 1\end{array}$ & $\begin{array}{c}\text { Paginação das obras } \\
\text { analisadas }\end{array}$ \\
\hline $\mathrm{EH} 1$ & $\begin{array}{l}\text { Desenvolvimento da Geometria } \\
\text { (mensuração). }\end{array}$ & $\mathrm{P} 1$ & $\begin{array}{l}\text { Eves }(2004, \text { p. } 57-58,60- \\
61) \\
\text { Boyer }(2012, \text { p. 33-36, 49- } \\
51,57,65-68,97)\end{array}$ \\
\hline $\mathrm{EH} 2$ & $\begin{array}{c}\text { Uso do empirismo como justificativa ao } \\
\text { conhecimento. }\end{array}$ & P1 & Boyer $(2012$, p. 51) \\
\hline EH3 & $\begin{array}{l}\text { Papiro de Ahmes ou Papiro Rhind (já } \\
\text { fazia uso da palavra "seqt", que } \\
\text { representava o afastamento horizontal } \\
\text { pela elevação vertical), e a Tábua } \\
\text { Plimpton } 322 .\end{array}$ & P1 & $\begin{array}{c}\text { Boyer }(2012, \text { p. } 36,47-48) \\
\text { Eves }(2004, \text { p. } 69-70,72- \\
76,82-84)\end{array}$ \\
\hline $\mathrm{EH} 4$ & $\begin{array}{c}\text { Divergência entre ciência e senso } \\
\text { comum (ciência livre). }\end{array}$ & P2 & Euclides (2009, p. 77) \\
\hline EH5 & Demonstração, axiomatização. & P3 & $\begin{array}{c}\text { Eves }(2004, \text { p. } 58,115) \\
\text { Euclides }(2009, \text { p. } 81-91) \\
\text { Boyer }(2012, \text { p. } 50-51,55, \\
73-74)\end{array}$ \\
\hline $\mathrm{EH} 6$ & $\begin{array}{l}\text { Hiparco organiza a primeira tábua } \\
\text { trigonométrica - Pai da Trigonometria. }\end{array}$ & P3 & $\begin{array}{l}\text { Eves }(2004, \text { p. } 202-204) \\
\text { Boyer }(2012, \text { p. } 124)\end{array}$ \\
\hline $\mathrm{EH} 7$ & $\begin{array}{c}\text { Ptolomeu organiza o Matematikes } \\
\text { Syntaxis (Almagesto). }\end{array}$ & P2 e P3 & $\begin{array}{c}\text { Eves (2004, p. 202-204) } \\
\text { Boyer (2012, p. 126-127, } \\
171-172)\end{array}$ \\
\hline EH8 & $\begin{array}{l}\text { Trigonometria como instrumento auxiliar } \\
\text { da Astronomia (Medida do tempo - }\end{array}$ & P2 & $\begin{array}{c}\text { Boyer }(2012, \text { p. } 123,128- \\
129,156,171,205)\end{array}$ \\
\hline
\end{tabular}


Universidade Federal da Grande Dourados

\begin{tabular}{|c|c|c|c|}
\hline & $\begin{array}{c}\text { relógio de Sol, estudo das fases da Lua, } \\
\text { estações do ano). }\end{array}$ & & \\
\hline EH9 & $\begin{array}{c}\text { Tratado dos Quadriláteros de Nasir al- } \\
\text { Din al-Tusi (Trigonometria desvinculada } \\
\text { da Astronomia). }\end{array}$ & P2 & $\begin{array}{c}\text { Eves (2004, p. 264) } \\
\text { Boyer (2012, p. 174-175, } \\
214-217)\end{array}$ \\
\hline EH10 & $\begin{array}{c}\text { De triangulis omnemodis libri quinque de } \\
\text { Regiomontanus. }\end{array}$ & P3 & $\begin{array}{c}\text { Eves (2004, p. 296-298, } \\
319)\end{array}$ \\
& Lei dos Senos. & Poyer (2012, p. 194-195) \\
\hline EH11 & \begin{tabular}{c} 
Boyer (2012, p. 158) \\
\hline
\end{tabular}
\end{tabular}

Fonte: Os autores (2019) com dados pinçados de Eves (2004), Euclides (2009) e Boyer (2012).

Mediante investigação na história da trigonometria e da não identificação de marcadores dos episódios históricos a respeito da DLS nas obras analisadas, percebeu-se a necessidade de estudos que contemplem a valorização do contexto histórico de surgimento da LS, uma vez que, embora seja indicado na resolução de alguns problemas que envolvem aplicações, desde o período de Tales (por volta de 600 a.C.) e Euclides (por volta de 300 a.C.), seu contexto de surgimento não está especificado.

\section{ANÁlise EPISTEMOLÓgICA dA DEMONSTRAÇÃo DA LEI dOS SENOS}

Partindo da reflexão de que "[...] é em termos de obstáculos que o problema do conhecimento científico deve ser colocado" (Bachelard, 1996, p. 17), pretende-se elucidar os fatores que interferem no processo de ensino e aprendizagem da DLS, especificando as condições que possam favorecer a aquisição desse conhecimento, expondo alternativas que possam facilitá-lo.

Antes de destacar esses fatores, é imprescindível esclarecer algumas definições que serão de fundamental importância para a compreensão da análise aqui proposta. Ao se pensar em fatores que interferem no processo de ensino e aprendizagem, não se pode negar a necessidade de desmistificar a confusão entre dificuldades e obstáculos epistemológicos. Nesse sentido,

[...] é no âmago do próprio ato de conhecer que aparecem, por uma espécie de imperativo funcional, lentidões e conflitos. É aí que mostraremos causas de estagnação e até de regressão, detectaremos causas de inércia às quais daremos o nome de obstáculos epistemológicos (Bachelard, 1996, p. 17).

A citação deixa bem clara a definição que o autor suscita sobre o que vêm a ser 


\section{Universidade Federal da Grande Dourados}

obstáculos epistemológicos, os quais devem ser conhecidos e analisados, a fim de serem superados, para que possam propiciar uma aquisição eficaz do conhecimento. Assim sendo, a identificação desses obstáculos teve como base os filtros destacados no Quadro 3, a seguir.

Quadro 3: Filtros para identificação dos obstáculos.

\begin{tabular}{|c|c|c|c|}
\hline \multirow{3}{*}{$\stackrel{\stackrel{0}{\stackrel{0}{ \pm}}}{\stackrel{ \pm}{i}}$} & $\mathrm{~F} 1$ & $\begin{array}{l}\text { Imperativo } \\
\text { funcional }\end{array}$ & $\begin{array}{l}\text { Pode-se entender como flexibilidade cognitiva (as possíveis interpretações } \\
\text { de um mesmo fato). }\end{array}$ \\
\hline & F2 & Lentidões & $\begin{array}{l}\text { Serão identificadas pela duração que uma interpretação perdurou ao longo } \\
\text { da história. }\end{array}$ \\
\hline & F3 & Conflitos & $\begin{array}{l}\text { Confronto de visões diferentes sobre o objeto matemático em jogo, que } \\
\text { sinaliza sua evolução. }\end{array}$ \\
\hline
\end{tabular}

Fonte: Os autores (2019).

De acordo com os entendimentos de obstáculos epistemológicos extraídos dos estudos de Bachelard (1996), e levando em consideração os filtros do Quadro 3, tevese em vista identificar, no decorrer do contexto histórico, indícios de obstáculos ao uso da Lei dos Senos pelas civilizações ao longo da história da matemática. "Nesse sentido, obstáculo é um conhecimento, uma concepção, e não uma dificuldade, ou uma falta de conhecimento" (Almouloud, 2007, p. 133). Os obstáculos, por sua vez, produzem respostas válidas em certo contexto e, às vezes, produzem respostas equivocadas.

Para identificação dos obstáculos envoltos no objeto matemático estudado (DLS), este estudo se alicerça nas pesquisas de Bachelard (1996) e Almouloud (2007) e na análise histórica da seção anterior.

No que concerne aos filtros listados no Quadro 3, nota-se uma possível articulação com as palavras-chave eleitas no Quadro 1. Desse modo, F1 se adéqua ao contexto que a palavra-chave P2 evidencia, marco das interpretações e definições que cada civilização apresentava acerca dos conhecimentos de trigonometria. Os primeiros estudos da trigonometria eram desvinculados da Astronomia. Como exemplo, tem-se a trigonometria grega, representada por sua essência especificamente geométrica. No que diz respeito aos povos hindus, pautavam-se em uma trigonometria mais 


\section{Universidade Federal da Grande Dourados}

aritmetizada. Nesse contexto, os árabes foram responsáveis por preservar os conhecimentos gregos mediante as traduções destes. São, portanto, povos que marcaram diferentes épocas e as interpretações a respeito dos conhecimentos ligados à trigonometria.

Com as observações do contexto histórico das obras analisadas e por meio das informações identificadas nas palavras-chave do Quadro 1, especificamente em P3, nota-se a evolução no uso do termo que representa a razão entre o cateto oposto ao ângulo de um triângulo e a hipotenusa. Essa razão era calculada por intermédio dos comprimentos das cordas para construção das tábuas de cordas, posteriormente chamadas de tábuas de senos, demarcando a flexibilidade cognitiva (F1), as interpretações e as formas diferenciadas para o mesmo tipo de cálculo.

Esses fatos iniciais na história da trigonometria, em parte registrados no Papiro Rhind e nas tábuas babilônicas, especialmente em Plimpton 322, aproximam também F1 de P1, que, no Quadro 1, marcam os primeiros vestígios do uso de elementos que caracterizam os conhecimentos de trigonometria, indícios nas civilizações babilônicas e egípcias e nos primeiros anos dos gregos. Esses elementos eram usados pelos povos hindus, assim como pelos gregos, como instrumentos que auxiliavam na resolução de problemas aplicáveis, especialmente, na Astronomia.

Apesar da não identificação de um marco inicial para o uso dos conhecimentos trigonométricos, busca-se nos vestígios, como no Plimpton 322, que data aproximadamente de 1900 e 1600 a.C., registros de que essas técnicas foram aperfeiçoadas. "Os astrônomos babilônicos dos séculos IV e V a.C. acumularam uma massa considerável de dados de observações [...]" (Eves, 2004, p. 202), o que foi de fundamental importância para o desenvolvimento astronômico.

Diante do exposto, percebeu-se a identificação do período em que perduraram os conhecimentos trigonométricos ao longo da história, demarcando o filtro F2. O F3 está bem representado em conformidade com a publicação do trabalho de Nasir al-Din alTusi (1250 a.C.), que marca o início do estudo da trigonometria não mais dependente da Astronomia. Assim, uma nova configuração e novos campos de investigação trigonométricos começam a ser descobertos, sinalizando a evolução desses 


\section{Universidade Federal da Grande Dourados}

conceitos.

Em face dos filtros do Quadro 3 e sua articulação com os marcos históricos dos conhecimentos de trigonometria, foram identificados os obstáculos listados a seguir.

Quadro 4: Principais obstáculos identificados para o desenvolvimento da DLS.

\begin{tabular}{|c|c|c|}
\hline Marcador & Obstáculo (OB) & Indicadores \\
\hline OB1 & Inexistência de um contexto que retrate a origem da Lei dos \\
Senos. & P1, P2, P3, P4 \\
\hline OB2 & Limitação da Lei dos Senos apenas como técnica na resolução \\
de problemas. & P4, EH8 \\
\hline
\end{tabular}

Fonte: Os autores (2019).

Por meio da investigação dos vestígios da Lei dos Senos no campo da trigonometria, foi possível identificar os dois obstáculos descritos no Quadro 4, uma vez que "Um dos pontos importantes de uma análise epistemológica é, ainda, permitir ao pesquisador em educação matemática perceber a diferença entre o saber 'científico' e o saber 'ensinado', pois esta análise lhe permite compreender a gênese da evolução do conhecimento científico" (Almouloud, 2007, p. 152).

Nesta análise, a ausência de marcos históricos, além de indicações do uso da LS apenas como instrumento/recurso na resolução de problemas, possibilita inferir a necessidade de um aprofundamento histórico a respeito dessa lei e do contexto lógico demonstrativo de sua construção axiomática, bem como investigar até que ponto as pesquisas pertencentes a esse campo de conhecimento depreenderam esforços para sanar lacunas na história desse objeto matemático.

\section{CONSIDERAÇÕES FINAIS}

Em face do levantamento de vestígios na história da trigonometria, com foco nos marcos da Lei dos Senos e no estudo epistemológico guiado pelas pesquisas de Bachelard (1996), foram identificados obstáculos epistemológicos (ver Quadro 4) que podem estar associados às dificuldades de compreensão do conteúdo em tela. Por meio das análises prévias feitas na seção 1, foram identificadas as características do objeto pesquisado, evidenciando os marcos e as justificativas apresentados na construção do conhecimento científico. 
No desenvolvimento da investigação, foi perceptível a grande necessidade de estudar as estruturas formais dos conteúdos matemáticos e a valorização na construção dos saberes tanto na Educação Básica quanto no Ensino Superior. Foi destacado como são apresentadas as abordagens históricas com ênfase na evolução do campo trigonométrico. A partir do estudo, foram constatados poucos indícios a respeito da Lei dos Senos, o que insere esse conteúdo em um patamar de necessidade de investigação.

Outrossim, os livros investigados apresentam a LS apenas como instrumento na resolução de problemas, não há uma exposição explícita acerca da sua origem, do porquê de seu uso e, quando é utilizada, se restringe a estudar a demonstração apenas em conteúdos geométricos, ficando evidente o pequeno foco nos conteúdos com maior ligação com a linguagem algébrica e abstrata da matemática, principalmente no que se refere aos conhecimentos trigonométricos.

Em vista disso, justifica-se ainda mais a necessidade de estudar esse campo do conhecimento que investiga as possibilidades de aprendizagem ao se trabalhar com a demonstração no trabalho com a Lei dos Senos. Portanto, explicita-se a necessidade de investigações nessa seara devido à ausência de aprofundamento sobre uma análise histórica e epistemológica que contemple entendimentos do cenário histórico da LS, os marcos de sua evolução e os conhecimentos envoltos nessa construção.

\section{REFERÊNCIAS}

Almouloud, S. A. (2007). Fundamentos da didática da matemática. Curitiba: UFPR.

Bachelard, G. (1996). A formação do espírito científico: contribuições para uma psicanálise do conhecimento. Rio de Janeiro: Contraponto.

Boyer, C. B. (2012). História da matemática. (E. F. Gomide, Trad.) São Paulo: Edgard Blücher. 
Domingues, H. H. (2002). A demonstração ao longo dos séculos. Bolema, 15, 55-67.

Euclides. (2009). Os Elementos. (I. Bicudo, Trad.) São Paulo: UNESP.

Eves, H. (2004). Introdução à história da matemática. (H. H. Domingues, Trad.) Campinas: UNICAMP.

Fiorentini, D., \& Lorenzato, S. (2009). Investigação em educação matemática: percursos teóricos e metodológicos (3ª ed.). Campinas/SP: Autores Associados.

Fonseca, L. S. (2011). Aprendizagem em trigonometria: obstáculos, sentidos e mobilizações. São Cristóvão: UFS.

Fonseca, L. S. (2012). Funções trigonométricas: elementos "de" \& "para" uma Engenharia Didática. São Paulo: Livraria da Física.

Fonseca, L. S. (2015). Um estudo sobre o ensino de funções trigonométricas no ensino médio e no ensino superiro no Brasil e França. Tese de doutorado, 495. São Paulo: Universidade Anhanguera de São Paulo.

Gil, A. C. (2002). Como elaborar um projeto de pesquisa (4⿳亠丷⿵冂⿱⺊口灬 ed.). São Paulo: Atlas.

lezzi, G. (2004). Fundamentos de matemática elementar 3: trigonometria (8ª ed.). São Paulo: Atual.

Lima, E. L., Carvalho, P. C., Wagner, E., \& Morgado, A. C. (2010). Temas e problemas. Rio de Janeiro: SBM. 


\section{Universidade Federal da Grande Dourados}

Lima, E. L., Carvalho, P. C., Wagner, E., \& Morgado, A. C. (2012). A matemática para ensino médio (10ª ed., Vol. 1). Rio de Janeiro: SBM.

Santos, M. P. (2019). Expectativas neurocognitivas da atenção em uma sequência de ensino para a habilitação do raciocínio axiomático durante a aprendizagem da demonstração da Lei dos Senos. Dissertação, 144. São Cristóvão, Sergipe, Brasil: Universidade Federal de Sergipe.

Silva, I. C., \& Pereira, A. C. (2016). XII Encontro Nacional de Educação Matemática. O estudo de fontes históricas: o caso do problema 56 do papiro de Rhind para o estudo de pirâmides. São Paulo, São Paulo, Brasil: SBEM. Fonte: http://www.sbembrasil.org.br/enem2016/anais/pdf/7046_3948_ID.pdf.

\section{CONTRIBUIÇÃO DOS AUTORES}

1ํ autor: conceitualização; curadoria de dados; análise formal; investigação; metodologia; administração do projeto; supervisão; visualização; redação - rascunho original; redação - revisão e edição.

2ำ autor: conceitualização; curadoria de dados; análise formal; investigação; metodologia; administração do projeto; supervisão; visualização; redação - rascunho original; redação - revisão e edição.

3ำ autor: conceitualização; curadoria de dados; análise formal; investigação; metodologia; administração do projeto; supervisão; visualização; redação - rascunho original; redação - revisão e edição. 